Europe PMC Funders Group

Author Manuscript

Nat Rev Neurol. Author manuscript; available in PMC 2012 May 11.

Published in final edited form as:

Nat Rev Neurol. ; 7(10): 584-594. doi:10.1038/nrneurol.2011.135.

\title{
Diagnosis and Treatment of Neurocysticercosis
}

\author{
Theodore E. Nash ${ }^{1}$ and Hector H. Garcia ${ }^{2,3}$ \\ ${ }^{1}$ Head, Gastrointestinal Parasites Section, Laboratory of Parasitic Diseases, National Institutes of \\ Allergy and Infectious Diseases, National Institutes of Health, Bethesda, Maryland, USA \\ ${ }^{2}$ Professor, Department of Microbiology, School of Sciences, and Director, Center for Global \\ Health - Tumbes, Universidad Peruana Cayetano Heredia, Lima, Perú \\ ${ }^{3}$ Head, Cysticercosis Unit, Instituto Nacional de Ciencias Neurologicas, Lima, Perú
}

\begin{abstract}
Neurocysticercosis, a major cause of acquired seizures and epiilepsy, is caused by infection with the larval cystic form of the tapeworm, Taenia solium. CT and MRI imaging, development of sensitive and specific diagnostic methods, and discovery of relatively effective anti-cestode drugs, revolutionized knowledge of the burden of infection and disease and led to effective treatments. Here we review the rationale of treatment, the essential role of inflammation in the genesis of disease and its exacerbation as a result of anti-parasitic treatment, and limitations in the efficacy of current anti-parasitic and anti-inflammatory treatments. The importance of "end stage" calcified granulomas as foci of seizures and epilepsy with and without perilesional edema in endemic populations has recently been recognized. New information indicates perilesional inflammation around some calcified foci is associated with seizures and perilesional edema, which suggests that anti-inflammatory treatments may play a role in controlling or preventing epilepsy in these patients. Most importantly, neurocysticercosis is one of the few diseases that can be eradicated, an accomplishment that would prevent millions of cases of epilepsy.
\end{abstract}

\section{Keywords}

Cysticercosis; neurocisticercosis; Taenia solium; seizures; albendazole; praziquantel

\section{Introduction}

Cysticercosis is an infection with the larval form of the pork tapeworm, Taenia solium, which resides in the small intestine of humans (see Box 1). Neurocysticercosis (NCC), invasion of the nervous system, is a major cause of adult acquired epilepsy and other neurological morbidity in many areas of the world (Figure 1).[1,2] Recent analyses calculated that $29 \%$ of epilepsy in endemic regions world wide is consistently caused by NCC, [3] a value that closely approximates estimates from Latin America.[4-7] Determination of prevalence of infection and disease has been estimated in relatively few regions and thus knowledge of the worldwide burden of disease is quite limited.[8] Overall,

Corresponding Author: Hector H. Garcia, MD, PhD, Department of Microbiology, School of Sciences, and Center for Global Health - Tumbes, Universidad Peruana Cayetano Heredia; and Cysticercosis Unit, Instituto Nacional de Ciencias Neurologicas. H. Delgado 430, SMP, Lima 31, Lima, Peru. Telephone + 511 3287360, Fax + 511 3284038, hgarcia@jhsph.edu.

Review Criteria.

Most information for this review was obtained from MEDLINE, through searchs of extensive files of the authors, or from their ongoing work. MEDLINE searchs were performed for the period between 1969 and 2011, using the search terms "cysticercosis", "neurocysticercosis", or "Taenia solium". Papers published in English or Spanish were reviewed. The final reference list was generated based on relevance to the topics covered on this review and publication date. 
1.7 to 3 million persons are conservatively estimated to suffer from epilepsy due to NCC worldwide.[9] Infections are common in Central and South America excluding Chile, Uruguay and Argentina, parts of the Caribbean, notably Haiti, India, Indonesia, most of Southeast Asia, part of China, many regions of non Muslim sub Saharan Africa, regions of Eastern Europe and residual transmission in Spain.[10-15] Although transmission is absent or rare in the US and most of Europe, NCC is still frequently diagnosed in migrant populations from endemic areas.[16-19] Seizures are still the most common manifestation, but a significant number present with complicated subarachnoid or ventricular disease requiring costly, sophisticated and/or prolonged treatments.

Despite impressive gains in diagnosis and availability of antiparasitic treatments, large gaps in both basic and practical knowledge about the parasite and host responses to it exist. Factors hindering further advances are the lack of clinically appropriate model infections, inability to maintain the life cycle experimentally, and the reliance on naturally infected humans as a source of infectious ova. Rodent model infections using other cestodes are useful but generally of limited usefulness. Even though pig infections are helpful, their failure to develop seizures limits their usefulness. Therefore, the most appropriate study of NCC is in humans. These studies are long and difficult, require sophisticated imaging and special tests, large numbers of personal and therefore considerable resources, which compared to other most other neglected diseases have not been forthcoming. It has been relegated along with echinococcosis as neglected neglected parasitic infections.

The tapeworm carrier is the sole source of infection and is likely most at risk and prone to high levels of exposure occasionally resulting in heavy infections including disseminated or encephalitic neurocysticercosis and complicated disease.[20-22] Family members and close contacts are also at considerable risk. Contamination of the environment, food and water as a lower level of exposure could account for the high prevalence of single enhancing lesions (SEL) in India.[23]

\section{Symptomatic disease \\ Types of NCC, pathogenesis, evolution}

After ingestion oncospheres are carried by the blood stream to various organs and lodge in the small blood vessels where they may or may not develop into viable cysts. Viable cysts form after 2-3 months. The distribution of cysts generally follows the distribution of blood in the brain. Parenchymal cysts are most common and in heavy infections frequently locate to the watershed areas between the white and gray matter. Why and how some cyst develop into large subarachnoid or racemose cysts is unknown but may occur following some form of degeneration and loss of growth inhibition. Cysts that lodge in the choroid plexus likely give rise to ventricular cysts. When small and dislodged these can pass down the ventricular system or become stuck and remain in the 4th ventricle, the most common location for ventricular cysts.

Signs and symptoms of NCC are particularly diverse and depend upon the number, location, growth, stage of degeneration and inflammation, host factors and parasite genotype.[2,24] Parenchymal disease (within the brain tissue) and extraparenchymal involvement, most commonly in the subarachnoid spaces, ventricles and spine, differ in a number of important ways (Table 1). However, many patients have multiple disease states and processes. A single patient may have multiple parenchymal cysts, some viable with little inflammation, others in various stages of degeneration with different degrees of inflammation, calcified lesions ventricular cysts, and hydrocephalus. To some degree the state of individual lesions are independent. 
Most of the pathophysiology directly or indirectly results from acute or chronic inflammation to degenerating cysts, membranes, cyst remnants and residual antigen. Controlling inflammation is a cornerstone to limiting morbidity and mortality. Less frequently encountered processes are mass effect and mechanical obstruction.[25] Many patients present with complicated intra and extraparenchymal disease, multiple locations in different stages of evolution and varying degrees of inflammation associated with each lesion or area of involvement.[26] It is the most severe manifestation that dictates the initial approach.

Presenting symptoms are variable and depend on the types of involvement and degree of inflammation. A recent summary of a large number of publications revealed that $78.8 \%$ of all patients presented with seizures, $37.9 \%$ headaches, $11.7 \%$ signs of intracranial hypertension, $7.9 \%$ meningitis, $2.8 \%$ cranial nerve palsies, $6 \%$ gait abnormalities, $16 \%$ focal deficits, $5.6 \%$ visual changes, and $4.5 \%$ altered mental state.[27] Seizures are more frequent between the second and fifth decades of life, and are most frequently generalized tonic-clonic.[10] Children present with a single degenerating cyst, or massive infections, more rarely calcifications and seldom with hydrocephalus or basal subrachnoid NCC.[28,29]

\section{Parenchymal NCC}

Parenchymal NCC most commonly presents with seizures, is relatively easy to treat, and except in heavy infections it has a relatively good prognosis. Cysts go from viable to a degenerating stage and then disappear or remain as a calcified scar.[30] (Figure 2).

Viable cysts-Viable non-degenerating cysts are not associated with evident inflammation. For reasons that are unclear or as a consequence of treatment, viable or developing cysts become recognized by the host initiating an intense inflammatory response and a stepwise series of degenerative changes.[31]

Degenerating cysts-As inflammation increases, the cyst contents become opaque. A granuloma forms around the cyst, first as a cellular infiltrate within the cyst and then fully formed with an inner epithelioid cellular layer. Over time the cyst becomes more disorganized with varying degrees of cyst remnants including recognizable cyst membranes and/or membranous-like ribbons, characteristic calcareous corpuscles, and varying degree of inflammatory reaction. Later, the granuloma decreases in size, becomes nodular instead of cystic with varying amounts of enhancement and sometimes edema, which gradually resolve with less propensity to cause seizures.[30,32]

Single enhancing lesions (SEL) are single degenerating cysts that usually present with seizures. Although neither imaging nor serology define the etiology of these unless typical cyst morphology is seen, studies in India, where this presentation is particularly common, proved most were a degenerating cysticercus if the lesion was less than $20 \mathrm{~mm}$, did not have gross edema with midline shift, no other cause was evident, and there was not subsequent growth. SELs have a relatively good prognosis but recurrent seizures increase for lesions that calcify and/or develop gliosis.[33-36]

Calcified cysts-Cysts become non visualizable and apparently resolve or the granuloma and cyst contents may hyalinize. Most of them calcify as seen best by by CT imaging.[37] In some cases intermittent flairs most likely of inflammation occur and are associated with seizures.[38-40] The reason for this to occur is unknown but is likely a combination of enhanced antigen accessibility to the host driving inflammation and/or loss of suppression of the host cellular response for reasons that are unclear.[32,41,42] Development of gliosis, almost certainly secondary to inflammation on the surrounding brain, increases the risk of 
epilepsy.[43,44] There are only a few documented descriptions of the pathology of calcifications, mostly describing hyalinized, calcified lesions with variable perilesional inflammation.[30,40,45-48]

\section{Extraparenchymal NCC}

Extraparenchymal NCC is not as common and less studied, more difficult to treat, and in general has a worse prognosis.[49,50] Extraparenchymal disease can be further subdivided into ventricular and subarachnoid involvement, the latter differing in its clinical presentation when affecting the convexity of the brain, the Sylvian fissure, or the basal subarachnoid space and cisterns (Figure 3).

Intraventricular NCC — Not infrequently, cysts lodge in the ventricles and cause mechanical obstruction with or without some degree of inflammation. Inflammation alone may result in hydrocephalus if not adequately suppressed. The fourth ventricle is most frequently involved although entrapment of the lateral or III ventricles also occurs. Unattached cysts may cause sudden positional mechanical obstruction causing nausea, vomiting and vertigo (Bruns' syndrome) or a more indolent presentation with symptoms of nausea, vomiting, headache and symptoms associated with hydrocephalus. A IVth ventricular cyst in a pregnant woman mimics emesis of pregnancy but is usually accompanied by headache.

Subarachnoid NCC of the brain convexity-Cysts on the convexity of the brain hemispheres usually behave like intraparenchymal cysts, are associated with seizures, and pass through the usual degenerative stages. They however may occasionally expand and grow as mass-occupying lesions.

Subarachnoid NCC of the Sylvian fissure-In the Sylvian fissure subarachnoid disease presents with cysts clumps or giant cysts, resulting in mass effects. Calcifications along the course of the middle cerebral artery suggest a chronic long-standing disease. Inflammation adjacent to the brain or other brain structures, fibrosis, nerve impingement, infarcts and less commonly cerebral hemorrhage further contribute to disease manifestations.[51]

Basal subarachnoid NCC-The most severe disease is due to basal subarachnoid NCC ("racemose"NCC), because of its location and ability to expand and multiply.[52] This aberrant growth form consists of vesicular enlargements and continuously proliferating parasite membranes within the spaces of the brain resulting in a complex vesicularmembranous tissue (grape-like hence the name racemose) and usually lacking a scolex. It can extensively involve the spaces of the brain, resulting in mass effect and/or inflammation. The inflammation directed to the parasite in the arachnoid space affects the meninges, foramina, adjacent brain, and nerves and vessels that course through the space, causing focal or diffuse arachnoiditis of the brain and spine. Eventually this results in mass effects, swelling, and fibrosis, which in turn cause infarcts, hydrocephalus, and nerve entrapments. Chiasmal involvement may lead to blindness. In some cases the cause of the meningitis may be unclear because no identifying features such as vesicular membranous structures are present.[53]

Basal subarachnoid NCC may also spread throughout the subarachnoid space and involve the spinal cord.[54] Although spinal involvement was considered unusual, a recent study found it in $50-70 \%$ of patients with basal subarachnoid disease, apparently asymptomatic in most cases (unpublished data, T. Nash \& H. Garcia, 2011). The degree of involvement and 
stage vary from arachnoiditis mostly in the cauda equina, minimal involvement with one or few cysts, to mass effects resulting in paralysis or uncommonly numerous cysts.[55]

\section{Diagnosis}

The diagnosis of neurocysticercosis rests on a constellation of findings including epidemiology, symptoms, signs, serology, brain imaging, and pathology if available. Although some findings are diagnostic, many times they are not. The diagnosis is established because the combination of findings is so unlikely in other disease states that the etiology of NCC is practically certain. Diagnostic criteria have been reported; although helpful they have not been systematically validated.

\section{Epidemiology}

Most patients have lived in endemic regions for long periods, usually in resource poor areas with on-going transmission. Lack of significant exposure is particularly helpful in nonendemic regions and should suggest an alternative diagnosis or search for non-traditional exposures. Patients may have had trivial exposure such as short-term travel to endemic areas or even with no discernible exposure. Orthodox Jews in New York were accidently infected by domestic employees from Central America who had taeniasis.[56]

\section{History and physical examination}

With the exception of ocular cysts, which can be characteristic if not diagnostic, signs and symptoms caused by NCC are usually not specific. The most common symptoms are seizures, focal findings, headache and intracranial hypertension. Seizures, usually focal with generalization or generalized are by far the most common manifestation. In a large majority, seizures are due to degenerating cysts or calcified granulomas, more rarely by infarcts in patients with subarachnoid involvement.[57] Focal neurological findings are less common, non-specific and due a variety of types of lesions and mechanisms. Headaches are frequent but are non-specific, and are commonly associated with seizures. In a community study, NCC was more common in patients with migranous headaches compared to those without headaches.[58] Hydrocephalus and intracranial hypertension are common in complicated NCC and may manifest as nausea, vomiting, headache, wide based gait, loss of consciousness, and other symptoms and findings. When appropriately evaluated, cognitive deficits and dementia are also frequently found.[59]

\section{Imaging}

CNS imaging is essential to establish the diagnosis and to determine the type of disease, emergency measures required, choice of treatments including amount and degree of immunosuppression, efficacy and duration of therapy. MRI is much superior to CT scanning to visualize brain structures and anatomy as well as cysts. However CT is superior to detect calcifications. CT imaging without contrast to detect calcification and a full MRI study with FIESTA or equivalent technique to define subarachnoid and ventricular disease are optimal. $[60,61]$

Imaging findings can be catalogued as consistent, probable or diagnostic. These have been reviewed elsewhere.[62] In the proper clinical context, roundish, $1-2 \mathrm{~cm}$ in diameter cysts with smooth walls and an eccentric dot representing the scolex are diagnostic. The presence of multiple types of compatible lesions or multiple similar lesions is helpful.

The process of cyst degeneration is best depicted by MRI examinations. Viable cysts appear clear to gross examination (same density as CSF), hypointense on T1 and FLAIR examinations. The first indication of degeneration is the presence of enhancement, which 
indicates dysfunction of the blood brain barrier, most likely due to pericyst inflammation around a still viable cyst. When the cyst becomes grossly opaque, the MRI appearance changes from no signal to a bright signal on T1 and FLAIR sequences accompanied by dense enhancement.[63]

Single enhancing lesions are a common diagnostic problem because the morphology is not conclusive and the serology is commonly negative.[64] In endemic regions they are conditionally considered NCC if they are $20 \mathrm{~mm}$ or less in diameter, not caused by another entity such as tuberculosis, and do not increase in size over time.[65]

Calcified cysts are typically buckshot-like-small, punctate, and round, although they may be much larger, chunky and irregular in shape at times. A single calcification is common in endemic populations, rare in non-endemic populations and therefore can be assumed to be due to NCC in the proper context. Multiple calcifications are more suggestive.[32]

\section{Serology}

Numerous serological tests measuring antibodies to $T$. solium have been reported. The best documented and most useful is a serum Western blot employing a specific fraction of $T$. solium cysts. Many of the components have been identified and cloned. The test is very specific for exposure and/or disease and to confirm the diagnosis.[66-70] However, it lacks sensitivity in patients with minimal disease defined as those with one viable or degenerating cyst. It may also be negative in individuals with only calcifications.[64] In endemic regions the test is useful in ruling out disease but is positive in a significant proportion of exposed individuals without disease.[71-73]

Antigen detection tests using monoclonal antibodies (developed against the closely related T. saginata) in a capture ELISA format have been developed. They are specific for current viable infection, which is their particular utility, but are not as sensitive as antibody assays. Antigen is commonly present in patients with subarachnoid disease but is less frequent in parenchymal disease. The concentration of antigen is higher in the CSF than the serum. Levels grossly correlate with the extent of involvement.[74,75] A major unsettled clinical issue is when to stop anthelminthic treatment in complicated subarachnoid disease. Serial measurements may be able to establish efficacy of treatment and parasite death.[76]

\section{Treatment}

Treatment of NCC depends upon the acuteness and severity of presentation, types and degree of involvement, stage of cyst degeneration and accompanying inflammation, and potential for future complications.[26,77-79] Treatment includes immediate measures to prevent undo morbidity or death, surgical procedures, anti-epileptic drugs (AED) to control seizures, corticosteroids to control inflammation, and anthelminthic medications to kill cysts. Few treatment modalities have been subjected to randomized studies; therefore, their degree of benefit and how they are best used are unclear. However, there is reasonable evidence and a great deal of anecdotal experience to support the use of anthelminthics to treat viable cysts usually accompanied with corticosteroids.

\section{Symptomatic treatment}

Patients with severe disease and life threatening complications require emergency treatment. In NCC this may be status epilepticus, intracranial hypertension with or without hydrocephalus, infarcts, mass effects, and focal neurological deficits. Anthelminthic treatment is rarely required before the patient is stabilized. In fact in some cases it may acutely aggravate an already critical situation. Identification and prompt relief of intracranial hypertension should be stressed. If there is an inflammatory component such as a 
degenerating cyst with edema and inflammation, acute or chronic hydrocephalus, large dose corticosteroids along with other supporting measures such as shunt placement are indicated.

Analgesics / Antiepileptic Drugs-Headache is a frequent complaint, alone or associated to seizures (post-ictal) or intracranial hypertension. Standard analgesics (paracetamol, tramadol, etc) are the first line of action for headache with usually a good clinical response. AED therapy is indicated in most patients with NCC and seizures since these are seizures secondary to an organic focus. Carbamazepine or phenytoin are most commonly used in endemic countries, mainly due to availability and costs. There are no formal studies of the efficacy of different AEDs in the treatment of epilepsy in NCC but anectodally does not appear to differ from the treatment of idiopathic epilepsy. Seizures are usually well controlled with monotherapy at standard doses.[80,81] In acute symptomatic seizures or seizures due inflammation may be benefit from corticosteroids or other antiinflammatory medication.

Anti-inflammatory drugs-Administration of corticosteroids to control treatmentinduced inflammation and many times to suppress inflammation during the natural course of disease is very common, almost universal. How best to employ corticosteroids has not been studied except in the treatment of SEL. Four studies showed that a limited course of corticosteroids plus AEDs decreased the number of subsequent seizures compared to AEDs alone. There is no standard steroid treatment regimen for multicystic disease. Strategies range from no use until seizures or other symptoms develop, to high dose prolonged administration before, during and after anthelminthic dosing.[82]

A trial to determine if an enhanced dosing of corticosteroids ( $8 \mathrm{mg}$ for 28 days followed by a 2 week taper) compared to standard dosing (6 mg for 10 days) results in decreased seizures in the treatment of parenchymal NCC is ongoing. Results are expected shortly. This is the first attempt to determine the utility, effectiveness and side effects of corticosteroid use when treating intraparenchymal NCC. Although corticosteroids in short courses are relatively safe, subarachnoid cysticercosis and occasionally complicated disease may require long-term high dose corticosteroids, with a large number of bothersome and occasionally life threatening side effects. Methotrexate was reported useful at $20 \mathrm{mg} / \mathrm{week}$ or less as a corticosteroid sparing agent.[83]

Patients commonly present with seizures associated with calcifications and perilesional edema.[41,42] Although the natural inclination is to use high dose corticosteroids, clinical benefit has not yet been proven and there are emerging observations of exacerbation of the original lesion and even other previously uninvolved calcifications when corticosteroids are decreased or stopped.[41] This "rebound", which appears to be due to an overcompensation following immunosuppression, also occurs in the treatment of viable cysts in the setting of anthelminthic treatment and high dose corticosteroids that are stopped abruptly.

\section{Anti-parasitic treatment}

Evidence suggesting clinical benefit efficacy of anthelminthic therapy is based upon results of double blinded randomized treatment studies in single and multicystic parenchymal disease, good clinical outcomes of non randomized series or studies with non randomized selected controls, and anecdotal experience of good clinical response following treatment of usually lethal or severe forms of NCC. Data on the benefit of anti-parasitic drugs in the treatment of SELs is conflicting and there are some trials that found no significant benefit of treatment.[84] The two anthelminthics most used (albendazole and praziquantel) are cysticidal, resulting in cyst resolution or eventual calcification. [85,86] However, despite reasonable proof of cysticidal efficacy, the clinical benefit of treatment was until recently 
not generally accepted because many patients developed treatment related exacerbation of disease and flawed design of early studies.[84,87]

Most recent treatment studies of parenchymal disease show a clinical benefit of anthelminthic therapy. The therapeutic approach to cystic disease, single enhancing lesions, or extraparenchymal NCC differs. A well-designed double-blinded randomized study comparing anti-parasitic-treated to untreated cystic NCC resulted in a significant decrease in generalized seizures and a decrease in partial seizures following the first month after treatment, confirming the conclusions of a number of earlier well-done but less conclusive studies.[57,88,89] In addition a meta analysis of treatment studies also showed clinical benefit.[90] SELs are single cysts that are in varying degrees of degeneration with inflammation. Whether anthelminthic treatment is efficacious in SELs is unclear because the results of many studies are disparate.[91-96]

Albendazole may be superior to praziquantel in usual dosing. Uncomplicated parenchymal disease is commonly treated with $15 \mathrm{mg} / \mathrm{kg}$ albendazole in 2 divided doses of $400 \mathrm{mg}$ with meals, for 8 days to 2 weeks. This regime may be under dosing some patients. Praziquantel is used at $50 \mathrm{mg} / \mathrm{kg}$ for 1-2 weeks usually with cimetidine and meals.[97] A short high dose regimen of $100 \mathrm{mg} / \mathrm{kg}$ praziquantel in three divided doses every 2 hours, followed by corticosteroids, has been found to be efficacious in patients with a single cyst but its efficacy is controversial in multicystic disease.[98,99] Although both drugs are cysticidal, their effects are commonly partial in the usual dosing. All commonly used regimens yield disappointingly low cure rates of around $60 \%$ decrease in parasites and $40 \%$ of complete clearance, resulting in retreatment. Levels of praziquantel and the ABZ metabolite albendazole sulfoxide are extremely variable from patient to patient and they are both decreased by AEDs and levels of praziquantel decreased by corticosteroids.[80,81,100,101] A potential approach would be to treat until the MRI shows initial degeneration of all the cysts and then continue treatment while steroids are tapered. Combined albendazole and praziquantel therapy seems safe and promising in initial reports.[81,102,103]

Unlike untreated NCC where cysts may degenerate at different times and rates, anti-parasitic treatment potentially induces inflammatory responses to all viable cysts at the same time. When cysts are numerous, large areas of the brain may be involved potentially leading to severe morbidity and death. However, the ability to kill most cysts, control the induced the inflammation and suppress seizure activity with corticosteroids over a relatively short period of time may be the major reason that the long-term seizure activity is decreased. Essentially, treatment eliminates viable cysts, which have the greatest potential to cause seizures when they degenerate. Patients with many viable lesions should be treated with particular caution and treatment of patients with disseminated disease or eye cysts is contraindicated. NCC encephalitis is treated primarily with corticosteroids. Treatment of patients with cysts lodged in critical areas such as the medulla and intraspinal lesions, require suppressing doses of corticosteroids and anthelminthics until the lesion resolves. Anthelminthic treatment is not indicated in calcified NCC because parasites are non-viable and only consist of calcified encapsulated cyst remnants along with varying degrees of host inflammatory reaction.

There are no controlled treatment trials of subarachnoid disease. Response to anthelminthic drugs is variable but as a rule requires long-term treatment and repeated assessments. Improvement is gauged by changes in clinical, radiological and in CSF parameters. One large series of medical treatment of giant cysts in the Sylvian fissure showed relatively good responses to repeated anthelminthic courses.[51] Basal subarachnoid NCC is usually more difficult to treat. Relapses commonly occur even years after apparent stabilization.

Nevertheless, in contrast to severe morbidity and frequent autopsy descriptions before the availability of anthelminthics, with persistent care and fastidious follow up patients usually 
show clinical improvement and survive with relatively little morbidity. Our current approach is usual anthelmintic dosing for two to three months and then reassess and retreat multiple times if necessary. Although not yet supported by controlled trials, increased dosing of praziquantel to $100 \mathrm{mg} / \mathrm{kg}$ or even combined therapy in usual concentrations and dosing may have higher cysticidal efficacy and could be considered for recurrent disease.

[81,104-110] Short term use of $30 \mathrm{mg} / \mathrm{kg} /$ day has also been tried without obvious increase in side effects.[111] Detection of cyst antigen in the serum and CSF assays may provide a useful tool for monitoring and follow up of these cases.[76,112]

\section{Surgery}

Surgical procedures are key in the treatment of complicated disease, including neuroendoscopy, open surgery, and shunt placement.[113] Neuroendoscopy is useful to remove cysts that are easily approached and causing symptoms; this may prevent prolonged use of corticosteroids and anthelminthics. There are no randomized studies of the treatment of ventricular disease. There is a general consensus that ventricular cysts should be removed if not adhered to the ependyma, preferably by neuroendoscopy. Even if successful, hydrocephalus sometimes develops anyway. Neuroendoscopical or open removal of large cysts that cause symptoms or will likely cause symptoms with treatment should also be considered.[114-118]

If a ventricular cyst is adherent or surgery unavailable, high dose corticosteroids with anthelminthics from 1-3 months or more may be considered. Continued anti-inflammatory drugs such as corticosteroids or methotrexate may be able to suppress continuing inflammation that leads to scarring and hydrocephalus. Non-obstructing cysts in the lateral ventricles can be treated medically but entrapment syndromes sometimes can result. Whether subsequent inflammatory reaction to remaining cysts, membranes or antigen contributes to subsequent hydrocephalus is not known. A relatively large treatment series of 4th ventricular lodged cysts, suggested medical therapy, sometimes requiring a shunt to control hydrocephalus, could successfully be employed. However, because even successfully treated patients with previous cysts in the IV ventricle sometimes require subsequent shunts and the long-term benefit is unclear, most experts recommend endoscopic or surgical removal. The advantages of this approach are immediate removal of the obstruction, control of inflammation by removal of the source of antigen and, because the cause of the inflammation is removed, less chance of developing obstructive and communicating hydrocephalus.[113]

\section{Conclusions}

Before 1970 NCC was uncommonly recognized, infrequently diagnosed and essentially untreatable. At present it is a commonly recognized infection and major cause of seizures in endemic regions, easily diagnosed by brain imaging, and medical treatment available. Despite these gains, there are large gaps in defining the worldwide burden of disease and infection, understanding pathophysiology of disease and genesis of epilepsy, and devising better and more effective treatments. The populations afflicted and burden of disease are only known for restricted studied populations but grossly underestimated worldwide. How to best use cysticidal agents is still not understood. Cure rates are low and long-term antiparasitic therapy frequently required for complicated disease. Moreover, their use is a double edge sword because they invoke an intense injurious inflammatory response that needs to be suppressed and complicates therapy. Inflammation is primarily responsible for most disease manifestations and how best to suppress it, is for the most part unstudied. Effective corticosteroid sparing/replacing agents need to be identified and incorporated into long-term management of ventricular and subarachnoid disease, the most severe types of NCC, whose treatment is based only on anecdotal experience. Calcified lesions are 
associated with most seizures in endemic populations, and 50\% of individuals with calcified NCC show perilesional edema at the time of a seizure recurrence. The pathophysiology is unclear but most likely some calcified lesions are inflammatory foci, which suggest antiinflammatory measures may treat and/or prevent seizures in these patients. Most importantly, neurocysticercosis is a preventable, eradicable infection. A commitment by international and national health agencies to control cysticercosis would prevent millions of cases of epilepsy.

\section{Biography}

Dr. Nash is a Principal Investigator in the Laboratory of Parasitic Diseases, National Institutes of Allergy and Infectious Diseases, National Institutes of Health, Bethesda, Maryland, USA. His research and clinical interests include Giardia and giardiasis and clinical and experimental aspects involving neurocysticercosis and Taenia solium. Topics of study include perilesional edema associated with calcified lesions as a cause of seizures and other symptoms, how best to control inflammation caused by degenerating parasites, use of novel drugs as corticosteroid sparing agents, and treatment of complicated subarachnoid neurocysticercosis.

Dr. Garcia is a Professor at the Department of Microbiology and Director of the Center for Global Health - Tumbes, at the Universidad Peruana Cayetano Heredia, and Head of the Cysticercosis Unit at the National Institute for Neurological Sciences in Lima, Peru. Also a Wellcome Trust International Senior Research Fellow and a Senior Member of the Cysticercosis Working Group in Peru, Dr. Garcia has an extensive academic production in cysticercosis and hydatid disease. The works of the CWGP include pivotal articles on diagnosis, treatment and control/elimination of $T$. solium.

\section{References}

1. Commission on Tropical Diseases of the International League Against Epilepsy. Relationship between epilepsy and tropical diseases. Commission on Tropical Diseases of the International League Against Epilepsy. Epilepsia. 1994; 35:89-93. [PubMed: 8112262]

2. Garcia HH, Del Brutto OH. Neurocysticercosis: updated concepts about an old disease. Lancet Neurol. 2005; 4:653-661. [PubMed: 16168934]

3. Ndimubanzi PC, Carabin H, Budke CM, Nguyen H, Qian YJ, Rainwater E, Dickey M, Reynolds S, Stoner JA. A systematic review of the frequency of neurocyticercosis with a focus on people with epilepsy. PLoS Negl Trop Dis. 2010; 4:e870. [PubMed: 21072231]

4. Montano SM, Villaran MV, Ylquimiche L, Figueroa JJ, Rodriguez S, Bautista CT, Gonzalez AE, Tsang VC, Gilman RH, Garcia HH. Neurocysticercosis: association between seizures, serology, and brain CT in rural Peru. Neurology. 2005; 65:229-233. [PubMed: 16043791]

5. Villaran MV, Montano SM, Gonzalvez G, Moyano LM, Chero JC, Rodriguez S, Gonzalez AE, Pan W, Tsang VC, Gilman RH, et al. Epilepsy and neurocysticercosis: an incidence study in a Peruvian rural population. Neuroepidemiology. 2009; 33:25-31. [PubMed: 19325247]

6. Medina MT, Duron RM, Martinez L, Osorio JR, Estrada AL, Zuniga C, Cartagena D, Collins JS, Holden KR. Prevalence, incidence, and etiology of epilepsies in rural Honduras: the Salama Study. Epilepsia. 2005; 46:124-131. [PubMed: 15660778]

7. Del Brutto OH, Santibanez R, Idrovo L, Rodriguez S, Diaz-Calderon E, Navas C, Gilman RH, Cuesta F, Mosquera A, Gonzalez AE, et al. Epilepsy and neurocysticercosis in Atahualpa: a doorto-door survey in rural coastal Ecuador. Epilepsia. 2005; 46:583-587. [PubMed: 15816956]

8. Budke CM, White AC, Garcia HH. Zoonotic larval cestode infections: neglected, neglected tropical diseases? PLoS Negl Trop Dis. 2009; 3:e319. [PubMed: 19238190]

9. Rajshekhar V, Joshi DD, Doanh NQ, van De N, Xiaonong Z. Taenia solium taeniosis/cysticercosis in Asia: epidemiology, impact and issues. Acta Trop. 2003; 87:53-60. [PubMed: 12781378] 
10. Del Brutto, OH.; Sotelo, J.; Roman, GC. Neurocysticercosis. A clinical handbook. Swets and Zeitliger; Lisse: 1997.

11. Schantz, PM.; Wilkins, PP.; Tsang, VCW. Immigrants, imaging and immunoblots: the emergence of neurocysticercosis as a significant public health problem. In: Scheld, WM.; Craig, WA.; Hughes, JM., editors. Emerging Infections. Vol. 2. ASM Press; 1998. p. 213-241.

12. Quet F, Guerchet M, Pion SD, Ngoungou EB, Nicoletti A, Preux PM. Meta-analysis of the association between cysticercosis and epilepsy in Africa. Epilepsia. 2010; 51:830-837. [PubMed: 19919664]

13. Praet N, Speybroeck N, Manzanedo R, Berkvens D, Nsame Nforninwe D, Zoli A, Quet F, Preux PM, Carabin H, Geerts S. The disease burden of Taenia solium cysticercosis in Cameroon. PLoS Negl Trop Dis. 2009; 3:e406. [PubMed: 19333365]

14. Winkler AS, Blocher J, Auer H, Gotwald T, Matuja W, Schmutzhard E. Epilepsy and neurocysticercosis in rural Tanzania-An imaging study. Epilepsia. 2009; 50:987-993. [PubMed: 19054402]

15. Winkler AS, Willingham AL 3rd, Sikasunge CS, Schmutzhard E. Epilepsy and neurocysticercosis in sub-Saharan Africa. Wien Klin Wochenschr. 2009; 121(Suppl 3):3-12. [PubMed: 19915809]

16. Serpa JA, Graviss EA, Kass JS, White AC Jr. Neurocysticercosis in Houston, Texas: an update. Medicine (Baltimore). 2010; 90:81-86. [PubMed: 21200189]

17. Sorvillo F, Wilkins P, Shafir S, Eberhard M. Public health implications of cysticercosis acquired in the United States. Emerg Infect Dis. 2010; 17:1-6. [PubMed: 21192847]

18. Raffaldi I, Scolfaro C, Mignone F, Aguzzi S, Denegri F, Tovo PA. An uncommon cause of seizures in children living in developed countries: neurocysticercosis -a case report. Ital J Pediatr. 2010; 37:9. [PubMed: 21266080]

19. Croker C, Reporter R, Mascola L. Use of statewide hospital discharge data to evaluate the economic burden of neurocysticercosis in Los Angeles County (1991-2008). Am J Trop Med Hyg. 2010; 83:106-110. [PubMed: 20595487]

20. Gilman RH, Del Brutto OH, Garcia HH, Martinez M, TheCysticercosis Working Group in Peru. Prevalence of taeniosis among patients with neurocysticercosis is related to severity of infection. Neurology. 2000; 55:1062. [PubMed: 11061275]

21. Sarti Gutierrez E, Schantz PM, Aguilera J, Lopez A. Epidemiologic observations on porcine cysticercosis in a rural community of Michoacan State, Mexico. Vet Parasitol. 1992; 41:195-201. [PubMed: 1502782]

22. Lescano AG, Garcia HH, Gilman RH, Gavidia CM, Tsang VC, Rodriguez S, Moulton LH, Villaran MV, Montano SM, Gonzalez AE. Taenia solium cysticercosis hotspots surrounding tapeworm carriers: clustering on human seroprevalence but not on seizures. PLoS Negl Trop Dis. 2009; 3:e371. [PubMed: 19172178]

23. Garcia HH, Gonzalez AE, Rodriguez S, Tsang VC, Pretell EJ, Gonzales I, Gilman RH. Neurocysticercosis: unraveling the nature of the single cysticercal granuloma. Neurology. 2010; 75:654-658. [PubMed: 20713953]

24. Verma A, Prasad KN, Gupta RK, Singh AK, Nyati KK, Rizwan A, Pandey CM, Paliwal VK. Tolllike receptor 4 polymorphism and its association with symptomatic neurocysticercosis. J Infect Dis. 2010; 202:1219-1225. [PubMed: 20807077]

25. Lobato RD, Lamas E, Portillo JM, Roger R, Esparza J, Rivas JJ, Munoz MJ. Hydrocephalus in cerebral cysticercosis. Pathogenic and therapeutic considerations. J Neurosurg. 1981; 55:786-793. [PubMed: 7310501]

26. Nash TE, Singh G, White AC, Rajshekhar V, Loeb JA, Proano JV, Takayanagui OM, Gonzalez AE, Butman JA, DeGiorgio C, et al. Treatment of neurocysticercosis: current status and future research needs. Neurology. 2006; 67:1120-1127. [PubMed: 17030744]

27. Carabin H, Ndimubanzi PC, Budke CM, Nguyen H, Qian Y, Cowan LD, Stoner JA, Rainwater E, Dickey M. Clinical manifestations associated with neurocysticercosis: a systematic review. PLoS Negl Trop Dis. 2011; 5:e1152. [PubMed: 21629722]

28. Antoniuk S, Bruck I, Santos LH, Souza LP, Fugimura S. Neurocysticercosis in children: clinical study and follow-up of 112 patients. Rev Neurol. 2006; 42(Suppl 3):S97-101. [PubMed: 16642459] 
29. Morales NM, Agapejev S, Morales RR, Padula NA, Lima MM. Clinical aspects of neurocysticercosis in children. Pediatr Neurol. 2000; 22:287-291. [PubMed: 10788745]

30. Escobar, A. The pathology of neurocysticercosis. In: Palacios, E.; Rodriguez-Carbajal, J.; Taveras, JM., editors. Cysticercosis of the central nervous system. Charles C. Thomas; 1983. p. 27-54.

31. Evans, CAW.; The Cysticercosis Working Group in Perú. The immunology of the host-parasite relationship in Taenia solium cysticercosis: implications for prevention and therapy. In: Garcia, HH.; Martinez, SM., editors. Taenia solium taeniasis/cysticercosis. edn Second. Universo; 1999. p. 25-37.

32. Nash TE, Del Brutto OH, Butman JA, Corona T, Delgado-Escueta A, Duron RM, Evans CA, Gilman RH, Gonzalez AE, Loeb JA, et al. Calcific neurocysticercosis and epileptogenesis. Neurology. 2004; 62:1934-1938. [PubMed: 15184592]

33. Rajshekhar, V.; Chandy, MJ. Solitary cysticercus granuloma: the disappearing lesion. Orient Longman; Chennai: 2000.

34. Singh G, Murthy JM. Solitary cysticercus granuloma-treatment with albendazole: what is the optimal duration? Neurol India. 2010; 58:507-508. [PubMed: 20739782]

35. Rajshekhar V, Haran RP, Prakash GS, Chandy MJ. Differentiating solitary small cysticercus granulomas and tuberculomas in patients with epilepsy. Clinical and computerized tomographic criteria. J Neurosurg. 1993; 78:402-407. [PubMed: 8433141]

36. Sharma P, Garg RK, Verma R, Singh MK, Shukla R. Risk of seizure recurrence in patients of newonset partial seizure having a solitary cysticercus granuloma of brain or normal neuroimaging. $\mathrm{J}$ Neurol Sci. 2010; 301:21-26. [PubMed: 21145565]

37. Kramer LD, Locke GE, Byrd SE, Daryabagi J. Cerebral cysticercosis: documentation of natural history with CT. Radiology. 1989; 171:459-462. [PubMed: 2704811]

38. Nash TE, Patronas NJ. Edema associated with calcified lesions in neurocysticercosis. Neurology. 1999; 53:777-781. [PubMed: 10489040]

39. Sheth TN, Pillon L, Keystone J, Kucharczyk W. Persistent MR contrast enhancement of calcified neurocysticercosis lesions. AJNR Am J Neuroradiol. 1998; 19:79-82. [PubMed: 9432161]

40. Ooi WW, Wijemanne S, Thomas CB, Quezado M, Brown CR, Nash TE. A Calcified Taenia solium Granuloma Associated with Recurrent Perilesional Edema Causing Refractory Seizures: Histopathological Features. Am J Trop Med Hyg. 2011 in press.

41. Nash TE, Pretell J, Garcia HH. Calcified cysticerci provoke perilesional edema and seizures. Clin Infect Dis. 2001; 33:1649-1653. [PubMed: 11595994]

42. Nash TE, Pretell EJ, Lescano AG, Bustos JA, Gilman RH, Gonzalez AE, Garcia HH. Perilesional brain oedema and seizure activity in patients with calcified neurocysticercosis: a prospective cohort and nested case-control study. Lancet Neurol. 2008; 7:1099-1105. [PubMed: 18986841]

43. Pradhan S, Kathuria MK, Gupta RK. Perilesional gliosis and seizure outcome: a study based on magnetization transfer magnetic resonance imaging in patients with neurocysticercosis. Ann Neurol. 2000; 48:181-187. [PubMed: 10939568]

44. Gupta RK, Kathuria MK, Pradhan S. Magnetisation transfer magnetic resonance imaging demonstration of perilesional gliosis--relation with epilepsy in treated or healed neurocysticercosis. Lancet. 1999; 354:44-45. [PubMed: 10406368]

45. Escobar, A.; Weidenheim, KM. The pathology of neurocysticercosis. In: Singh, G.; Prabhakar, S., editors. Taenia solium cysticercosis. From basic to clinical science. CABI Publishing; 2002. p. 289-305.

46. Henneberg, R. Die tierischen parasiten des zentralnervensystem. In: Lewandowsky, M., editor. Handbuch der neurologie. Vol. III. Verlag Von Julius Springer; 1912. p. 643-712.

47. Rabiela-Cervantes, MTR.; Rivas-Hernandez, A.; Rodriguez-Ibarra, J.; Castillo-Medina, S.; Cancino, FdM. Anatomopathological aspects of human brain cysticercosis. In: Flisser, A.; Willms, K.; J.P., L.; Larralde, C.; Ridaura, C.; Beltran, F., editors. Cysticercosis: Present State of Knowledge and Perspectives. Academic Press; 1982. p. 179-200.

48. Marquez-Monter, H. Cysticercosis. In: Marcial-Rojas, R., editor. Pathology of Protozoal and Helminthic Diseases. Williams \& Wilkins; 1971. p. 592-617.

49. Figueroa JJ, Davis LE, Magalhaes A. Extraparenchymal neurocysticercosis in albuquerque, New Mexico. J Neuroimaging. 2010; 21:38-43. [PubMed: 20002970] 
50. Bandres JC, White AC Jr. Samo T, Murphy EC, Harris RL. Extraparenchymal neurocysticercosis: report of five cases and review of management. Clin Infect Dis. 1992; 15:799-811. [PubMed: 1445979]

51. Proano JV, Madrazo I, Avelar F, Lopez-Felix B, Diaz G, Grijalva I. Medical treatment for neurocysticercosis characterized by giant subarachnoid cysts. N Engl J Med. 2001; 345:879-885. [PubMed: 11565520]

52. Bickerstaff ER, Cloake PCP, Hughes B, Smith WT. The racemose form of cerebral cysticercosis. Brain. 1952; 75:1-16. [PubMed: 14916052]

53. Cardenas G, Jung H, Rios C, Fleury A, Soto-Hernandez JL. Severe cysticercal meningitis: clinical and imaging characteristics. Am J Trop Med Hyg. 2010; 82:121-125. [PubMed: 20065006]

54. Lim BC, Lee RS, Lim JS, Cho KY. A case of neurocysticercosis in entire spinal level. J Korean Neurosurg Soc. 2010; 48:371-374. [PubMed: 21113369]

55. Boulos MI, Aviv RI, Lee L. Spinal neurocysticercosis manifesting as recurrent aseptic meningitis. Can J Neurol Sci. 2010; 37:878-880. [PubMed: 21059558]

56. Schantz PM, Moore AC, Munoz JL, Hartman BJ, Schaefer JA, Aron AM, Persaud D, Sarti E, Wilson M, Flisser A. Neurocysticercosis in an Orthodox Jewish community in New York City. N Engl J Med. 1992; 327:692-695. [PubMed: 1495521]

57. Del Brutto OH, Santibanez R, Noboa CA, Aguirre R, Diaz E, Alarcon TA. Epilepsy due to neurocysticercosis: analysis of 203 patients. Neurology. 1992; 42:389-392. [PubMed: 1736171]

58. Cruz ME, Cruz I, Preux PM, Schantz P, Dumas M. Headache and cysticercosis in Ecuador, South America. Headache. 1995; 35:93-97. [PubMed: 7737869]

59. Ciampi de Andrade D, Rodrigues CL, Abraham R, Castro LH, Livramento JA, Machado LR, Leite $\mathrm{CC}$, Caramelli P. Cognitive impairment and dementia in neurocysticercosis: a cross-sectional controlled study. Neurology. 2010; 74:1288-1295. [PubMed: 20404310]

60. Garcia HH, Del Brutto OH. Imaging findings in neurocysticercosis. Acta Tropica. 2003; 87:71-78. [PubMed: 12781380]

61. George U, Bansal G, Rathore S. MR spectroscopy aids diagnosis in subarachnoid space cysticercosis. Neurol India. 2010; 58:957-958. [PubMed: 21150072]

62. Del Brutto OH, Rajshekhar V, White AC Jr. Tsang VC, Nash TE, Takayanagui OM, Schantz PM, Evans CA, Flisser A, Correa D, et al. Proposed diagnostic criteria for neurocysticercosis. Neurology. 2001; 57:177-183. [PubMed: 11480424]

63. Dumas JL, Vusy JM, Belin C. Parenchymal neurocysticercosis: follow up and staging by MRI. Neuroradiology. 1997; 39:12-16. [PubMed: 9121640]

64. Wilson M, Bryan RT, Fried JA, Ware DA, Schantz PM, Pilcher JB, Tsang VC. Clinical evaluation of the cysticercosis enzyme-linked immunoelectrotransfer blot in patients with neurocysticercosis. J Infect Dis. 1991; 164:1007-1009. [PubMed: 1940452]

65. Rajshekhar V, Chandy MJ. Validation of diagnostic criteria for solitary cerebral cysticercus granuloma in patients presenting with seizures. Acta Neurol Scand. 1997; 96:76-81. [PubMed: 9272181]

66. Scheel CM, Khan A, Hancock K, Garcia HH, Gonzalez AE, Gilman RH, Tsang VC. Serodiagnosis of neurocysticercosis using synthetic $8-\mathrm{kD}$ proteins: comparison of assay formats. Am J Trop Med Hyg. 2005; 73:771-776. [PubMed: 16222024]

67. Greene RM, Hancock K, Wilkins PP, Tsang VC. Taenia solium: molecular cloning and serologic evaluation of 14- and 18-kDa related, diagnostic antigens. J Parasitol. 2000; 86:1001-1007. [PubMed: 11128471]

68. Handali S, Gonzalez AE, Hancock K, Garcia HH, Roberts JM, Gilman RH, Tsang VC. Porcine antibody responses to taenia solium antigens rGp50 and sTs18var1. Am J Trop Med Hyg. 2004; 71:322-326. [PubMed: 15381814]

69. Handali S, Klarman M, Gaspard AN, Dong XF, Laborde R, Noh J, Lee YM, Rodriguez S, Gonzalez AE, Garcia HH, et al. Development and evaluation of a magnetic immunochromatographic test to detect Taenia solium, which causes taeniasis and neurocysticercosis in humans. Clin Vaccine Immunol. 2010; 17:631-637. [PubMed: 20181766]

70. Handali S, Klarman M, Gaspard AN, Noh J, Lee YM, Rodriguez S, Gonzalez AE, Garcia HH, Gilman RH, Tsang VC, et al. Multiantigen print immunoassay for comparison of diagnostic 
antigens for Taenia solium cysticercosis and taeniasis. Clin Vaccine Immunol. 2010; 17:68-72. [PubMed: 19906893]

71. Garcia HH, Gonzalez AE, Del Brutto OH, Tsang VC, Llanos-Zavalaga F, Gonzalvez G, Romero J, Gilman RH. Strategies for the elimination of taeniasis/cysticercosis. J Neurol Sci. 2007; 262:153157. [PubMed: 17681546]

72. Diaz F, Garcia HH, Gilman RH, Gonzales AE, Castro M, Tsang VC, Pilcher JB, Vasquez LE, Lescano M, Carcamo C, et al. The Cysticercosis Working Group in Peru. Epidemiology of taeniasis and cysticercosis in a Peruvian village. Am J Epidemiol. 1992; 135:875-882. [PubMed: 1585900]

73. Diaz JF, Verastegui M, Gilman RH, Tsang VC, Pilcher JB, Gallo C, Garcia HH, Torres P, Montenegro T, Miranda E, The Cysticercosis Working Group in Peru (CWG). Immunodiagnosis of human cysticercosis (Taenia solium): a field comparison of an antibody-enzyme-linked immunosorbent assay (ELISA), an antigen-ELISA, and an enzyme-linked immunoelectrotransfer blot (EITB) assay in Peru. Am J Trop Med Hyg. 1992; 46:610-615. [PubMed: 1599056]

74. Rodriguez S, Dorny P, Tsang VC, Pretell EJ, Brandt J, Lescano AG, Gonzalez AE, Gilman RH, Garcia HH. Detection of Taenia solium antigens and anti-T. solium antibodies in paired serum and cerebrospinal fluid samples from patients with intraparenchymal or extraparenchymal neurocysticercosis. J Infect Dis. 2009; 199:1345-1352. [PubMed: 19358669]

75. Bobes RJ, Hernandez M, Marquez C, Fragoso G, Garcia E, Parkhouse RM, Harrison LJ, Sciutto E, Fleury A. Subarachnoidal and intraventricular human neurocysticercosis: application of an antigen detection assay for the diagnosis and follow-up. Trop Med Int Health. 2006; 11:943-950. [PubMed: 16772017]

76. Zamora H, Castillo Y, Garcia HH, Pretell J, Rodriguez S, Dorny P, Gonzalez AE, Gilman RH, Tsang VCW, Brandt J. Drop in antigen levels following successful treatment of subarachnoid neurocysticercosis. American Journal of Tropical Medicine and Hygiene. 2005; 73:S41.

77. Sinha S, Sharma BS. Neurocysticercosis: a review of current status and management. J Clin Neurosci. 2009; 16:867-876. [PubMed: 19394828]

78. Garcia HH, Evans CA, Nash TE, Takayanagui OM, White AC Jr. Botero D, Rajshekhar V, Tsang VC, Schantz PM, Allan JC, et al. Current consensus guidelines for treatment of neurocysticercosis. Clin Microbiol Rev. 2002; 15:747-756. [PubMed: 12364377]

79. Singh G, Rajshekhar V, Murthy JM, Prabhakar S, Modi M, Khandelwal N, Garcia HH. A diagnostic and therapeutic scheme for a solitary cysticercus granuloma. Neurology. 2010; 75:2236-2245. [PubMed: 21172847]

80. Bittencourt PRM, Gracia CM, Martins R, Fernandes AG, Diekmann HW, Jung W. Phenytoin and carbamazepine decrease oral bioavailability of praziquantel. Neurology. 1992; 42:492-495. [PubMed: 1549207]

81. Garcia HH, Lescano AG, Lanchote V, Pretell EJ, Gonzales I, Bustos J, Takayanagui OM, Bonato P, Horton J, Saavedra H, et al. Pharmacokinetics of Combined Treatment with Praziquantel and Albendazole in Neurocysticercosis. Br J Clin Pharmacol. 2011

82. Mall RK, Agarwal A, Garg RK, Kar AM, Shukla R. Short course of prednisolone in Indian patients with solitary cysticercus granuloma and new-onset seizures. Epilepsia. 2003; 44:13971401. [PubMed: 14636346]

83. Mitre E, Talaat KR, Sperling MR, Nash TE. Methotrexate as a corticosteroid-sparing agent in complicated neurocysticercosis. Clin Infect Dis. 2007; 44:549-553. [PubMed: 17243058]

84. Carpio A, Santillan F, Leon P, Flores C, Hauser WA. Is the course of neurocysticercosis modified by treatment with antihelminthic agents? Arch Intern Med. 1995; 155:1982-1988. [PubMed: 7575052]

85. Carpio A, Kelvin EA, Bagiella E, Leslie D, Leon P, Andrews H, Hauser WA. Effects of albendazole treatment on neurocysticercosis: a randomised controlled trial. J Neurol Neurosurg Psychiatry. 2008; 79:1050-1055. [PubMed: 18495737]

86. Gonzalez AE, Falcon N, Gavidia C, Garcia HH, Tsang VC, Bernal T, Romero M, Gilman RH. Time-response curve of oxfendazole in the treatment of swine cysticercosis. Am J Trop Med Hyg. 1998; 59:832-836. [PubMed: 9840607] 
87. Del Brutto OH. Medical treatment of cysticercosis--effective. Arch Neurol. 1995; 52:102-104. [PubMed: 7826268]

88. Garcia HH, Pretell EJ, Gilman RH, Martinez SM, Moulton LH, Del Brutto OH, Herrera G, Evans CA, Gonzalez AE. A trial of antiparasitic treatment to reduce the rate of seizures due to cerebral cysticercosis. N Engl J Med. 2004; 350:249-258. [PubMed: 14724304]

89. Vazquez V, Sotelo J. The course of seizures after treatment for cerebral cysticercosis. N Engl J Med. 1992; 327:696-701. [PubMed: 1495522]

90. Del Brutto OH, Roos KL, Coffey CS, Garcia HH. Meta-analysis: Cysticidal drugs for neurocysticercosis: albendazole and praziquantel. Ann Intern Med. 2006; 145:43-51. [PubMed: 16818928]

91. Baranwal AK, Singhi PD, Khandelwal N, Singhi SC. Albendazole therapy in children with focal seizures and single small enhancing computerized tomographic lesions: a randomized, placebocontrolled, double blind trial. Pediatr Infect Dis J. 1998; 17:696-700. [PubMed: 9726343]

92. Kaur M, Mahajan RC, Malla N. Diagnostic accuracy of rapid enzyme linked immunosorbent assay for the diagnosis of human hydatidosis. Indian J Med Res. 1999; 110:18-21. [PubMed: 10709334]

93. Kaur P, Dhiman P, Dhawan N, Nijhawan R, Pandit S. Comparison of 1 week versus 4 weeks of albendazole therapy in single small enhancing computed tomography lesion. Neurol India. 2010; 58:560-564. [PubMed: 20739792]

94. Goel D, Mittal M, Bansal KK, Singhal A. Natural history of solitary cerebral cysticercosis cases after albendazole therapy: a longitudinal follow-up study from India. Acta Neurol Scand. 2010; 121:204-208. [PubMed: 19951271]

95. Padma MV, Behari M, Misra NK, Ahuja GK. Albendazole in single CT ring lesions in epilepsy. Neurology. 1994; 44:1344-1346. [PubMed: 8035946]

96. Rajshekhar V. Albendazole therapy in patients with solitary cerebral cysticercus granuloma. Is it effective? J Neurol Neurosurg Psychiatry. 2008; 79:238-239. [PubMed: 18281444]

97. Sotelo J, del Brutto OH, Penagos P, Escobedo F, Torres B, Rodriguez-Carbajal J, RubioDonnadieu F. Comparison of therapeutic regimen of anticysticercal drugs for parenchymal brain cysticercosis. J Neurol. 1990; 237:69-72. [PubMed: 2192018]

98. Corona T, Lugo R, Medina R, Sotelo J. Single-day praziquantel therapy for neurocysticercosis. N Engl J Med. 1996; 334:125. [PubMed: 8531958]

99. Pretell EJ, Garcia HH, Gilman RH, Saavedra H, Martinez M, The Cysticercosis Working Group in Peru. Failure of one-day praziquantel treatment in patients with multiple neurocysticercosis lesions. Clin Neurol Neurosurg. 2001; 103:175-177. [PubMed: 11532559]

100. Castro N, Marquez-Caraveo C, Brundage RC, Gonzalez-Esquivel D, Suarez AM, Gongora F, Jara A, Urizar J, Lanao JM, Jung H. Population pharmacokinetics of albendazole in patients with neurocysticercosis. Int J Clin Pharmacol Ther. 2009; 47:679-685. [PubMed: 19840532]

101. Jung, H.; Gonzalez, D. Pharmacology of antycisticercal therapy. In: Singh, G.; Prabhakar, S., editors. Taenia solium cysticercosis. From basic to clinical science. CABI Publishing; 2002. p. 363-374.

102. Guo DM, Xie SP, Jia JP. Therapeutic efficacy of praziquantel, albendazole and a combination of the two drugs in cysticercosis. Zhongguo Ji Sheng Chong Xue Yu Ji Sheng Chong Bing Za Zhi. 2003; 21:187-188. [PubMed: 14628357]

103. Kaur S, Singhi P, Singhi S, Khandelwal N. Combination therapy with albendazole and praziquantel versus albendazole alone in children with seizures and single lesion neurocysticercosis: a randomized, placebo-controlled double blind trial. Pediatr Infect Dis J. 2009; 28:403-406. [PubMed: 19325515]

104. Bittencourt PR, Gracia CM, Gorz AM, Mazer S, Oliveira TV. High-dose praziquantel for neurocysticercosis: efficacy and tolerability. Eur Neurol. 1990; 30:229-234. [PubMed: 2209679]

105. Bittencourt PR, Gracia CM, Gorz AM, Oliveira TV. High-dose praziquantel for neurocysticercosis: serum and CSF concentrations. Acta Neurol Scand. 1990; 82:28-33. [PubMed: 2239133]

106. Overbosch D, van de Nes JC, Groll E, Diekmann HW, Polderman AM, Mattie H. Penetration of praziquantel into cerebrospinal fluid and cysticerci in human cysticercosis. Eur J Clin Pharmacol. 1987; 33:287-292. [PubMed: 3691616] 
107. Yee T, Barakos JA, Knight RT. High-dose praziquantel with cimetidine for refractory neurocysticercosis: a case report with clinical and MRI follow-up. West J Med. 1999; 170:112115. [PubMed: 10063399]

108. Lima RM, Ferreira MA, de Jesus Ponte Carvalho TM, Dumet Fernandes BJ, Takayanagui OM, Garcia HH, Coelho EB, Lanchote VL. Albendazole-praziquantel interaction in healthy volunteers: kinetic disposition, metabolism and enantioselectivity. Br J Clin Pharmacol. 2011; 71:528-535. [PubMed: 21395645]

109. Agapejev S, Da Silva MD, Ueda AK. Severe forms of neurocysticercosis: treatment with albendazole. Arq Neuropsiquiatr. 1996; 54:82-93. [PubMed: 8736150]

110. Cardenas G, Carrillo-Mezo R, Jung H, Sciutto E, Hernandez JL, Fleury A. Subarachnoidal Neurocysticercosis non-responsive to cysticidal drugs: a case series. BMC Neurol. 2010; 10:16. [PubMed: 20202200]

111. Gongora-Rivera F, Soto-Hernandez JL, Gonzalez Esquivel D, Cook HJ, Marquez-Caraveo C, Hernandez Davila R, Santos-Zambrano J. Albendazole trial at 15 or $30 \mathrm{mg} / \mathrm{kg} /$ day for subarachnoid and intraventricular cysticercosis. Neurology. 2006; 66:436-438. [PubMed: 16382035]

112. Garcia HH. Serological diagnosis and follow-up of severe neurocysticercosis using HP10 antigen detection. Nat Clin Pract Neurol. 2007; 3:488-489. [PubMed: 17637728]

113. Rajshekhar V. Surgical management of neurocysticercosis. Int J Surg. 2010; 8:100-104. [PubMed: 20045747]

114. Torres-Corzo JG, Tapia-Perez JH, Vecchia RR, Chalita-Williams JC, Sanchez-Aguilar M, Sanchez-Rodriguez JJ. Endoscopic management of hydrocephalus due to neurocysticercosis. Clin Neurol Neurosurg. 2010; 112:11-16. [PubMed: 19767141]

115. Jimenez-Vazquez OH, Nagore N. Cisternal neurocysticercosis. Br J Neurosurg. 2008; 22:774775. [PubMed: 19085362]

116. Jimenez-Vazquez OH, Nagore N. Role of neuroendoscopy in the treatment of large viable cysticerci in the brain parenchyma. Br J Neurosurg. 2008; 22:682-683. [PubMed: 18661313]

117. Bergsneider M. Endoscopic removal of cysticercal cysts within the fourth ventricle. Technical note. J Neurosurg. 1999; 91:340-345. [PubMed: 10433327]

118. Bergsneider M, Holly LT, Lee JH, King WA, Frazee JG. Endoscopic management of cysticercal cysts within the lateral and third ventricles. J Neurosurg. 2000; 92:14-23. [PubMed: 10616077] 


\section{BOX 1 - LIFE CYCLE}

- Agent: Taenia solium, cestode worm ("pork tapeworm”)

- Location - small intestine of humans, their sole host.

- Mature tapeworms are 2-4 meters long and consist of a head containing 4 suckers and a rostellum of hooklets for grasping, a neck and a series of increasingly mature proglottids. Liberated ova and/or segments of terminal mature proglottids are shed in feces.

- Taeniasis infection: The adult tapeworm develops only in the intestine of a human host, after ingestion of raw or poorly cooked infected pork. Cysts evaginate in the upper small intestine, attach to the mucosa, and develop into adult tapeworms.

- Cysticercosis (larval form) infection: After ingestion by the intermediate host, usually free roaming pigs, the ova hatch, invade the intestines and are then infective embryos are carried by the blood stream throughout the body. Larval cysts mature in 2-3 months. Although cysts may be found in any blood supplied tissue, they are most commonly found in muscles, subcutaneous tissue and brain. Humans develop cysticercosis, like the pig intermediate host, after the accidental ingestion of ova. Because each proglottid contains between 30,000-50,000 ova, the human tapeworm carrier is very infectious, the "typhoid Mary" of parasitology. 


\section{Key Points}

- Taenia solium neurocysticercosis is a common cause of seizure disorders worldwide.

- Intraparenchymal NCC courses mostly with seizures; extraparenchymal NCC may cause mass effects and hydrocephalus and has a much worse prognosis.

- Management includes symptomatic therapy commonly including antiepileptic drugs and steroids as anti-inflammatory agents, and anti-parasitic drugs in most cases with viable parasites.

- Most treatment recommendations are based on expert opinion or descriptive literature. Only a few controlled studies of antiparasitic drugs or steroids exist, mostly in patients with a single degenerating lesion.

- NCC could provide a useful model to study susceptibility and genesis of epilepsy.

- NCC is a preventable and likely eradicable cause of seizures and epilepsy. 


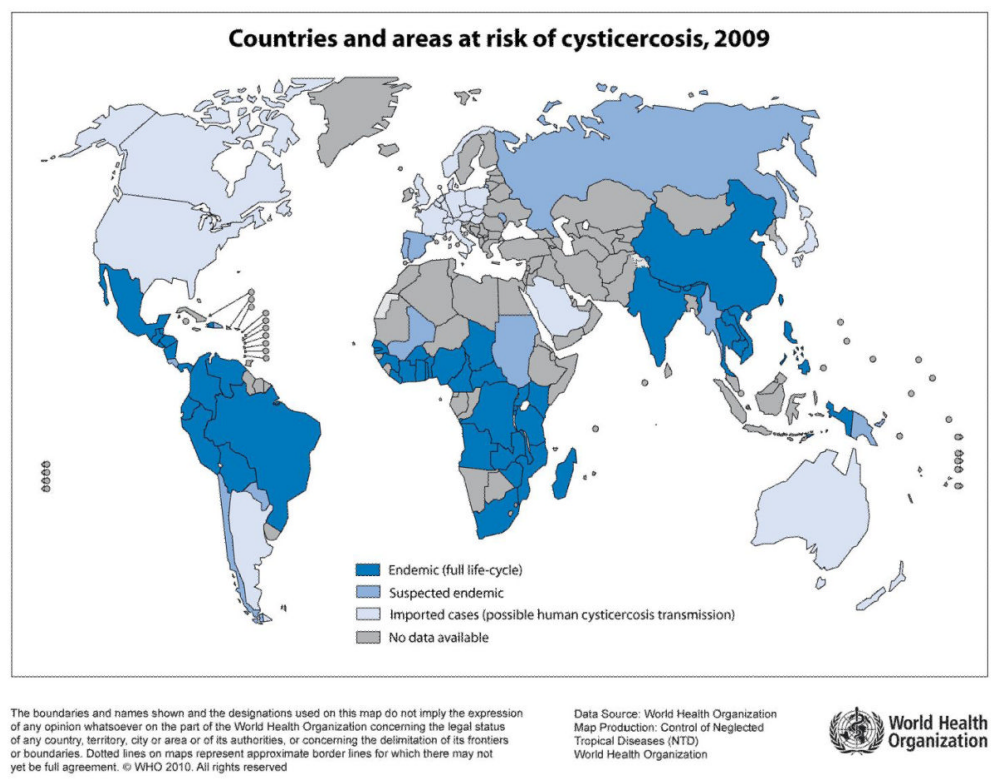

Figure 1.

World map showing the distribution of Taenia solium taeniasis/cysticercosis transmission (Taken from WHO - Control of Neglected Diseases website (http://gamapserver.who.int/ mapLibrary/Files/Maps/Global_cysticercosis_2009.png), permission needs to be requested. 

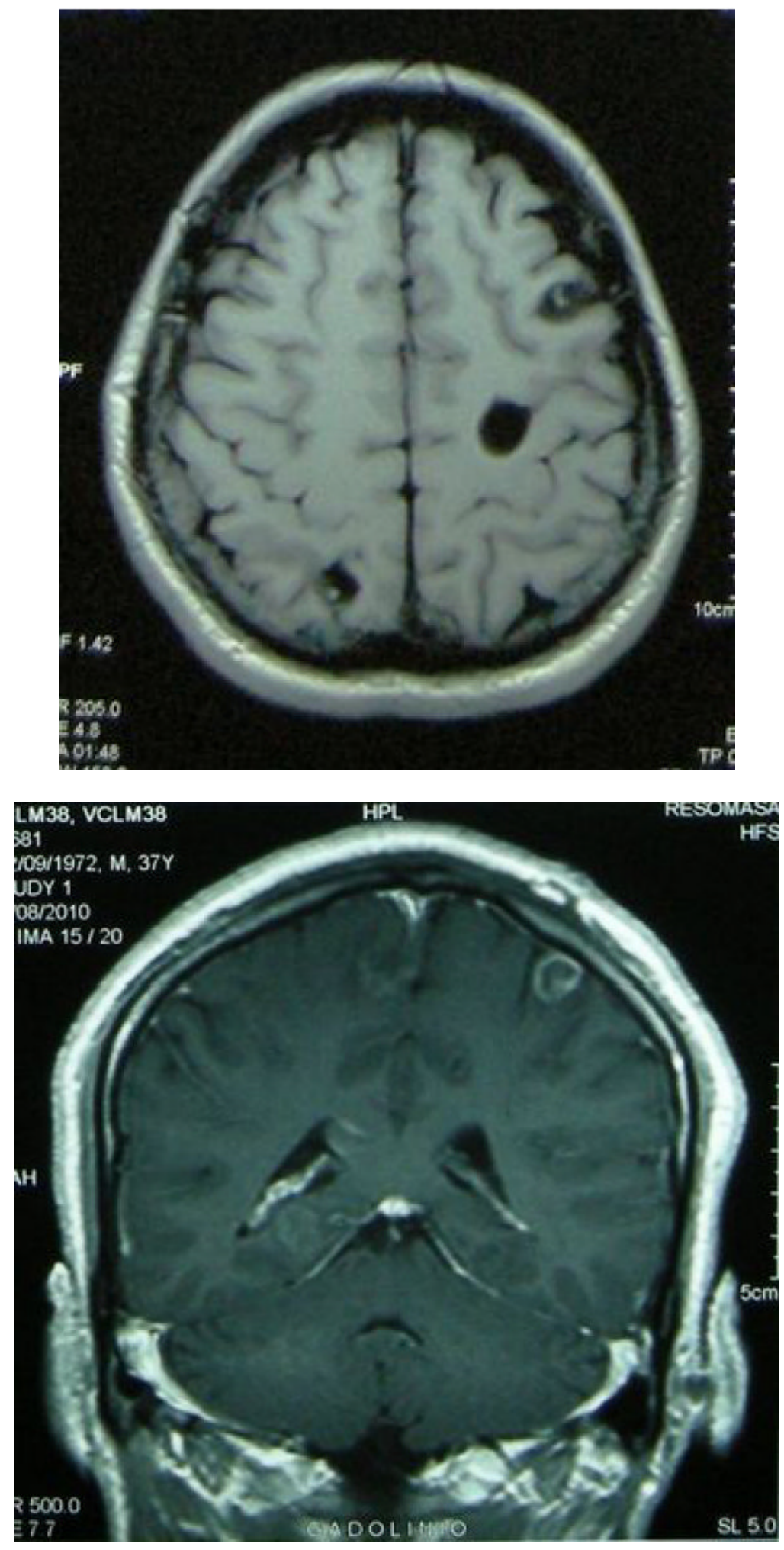

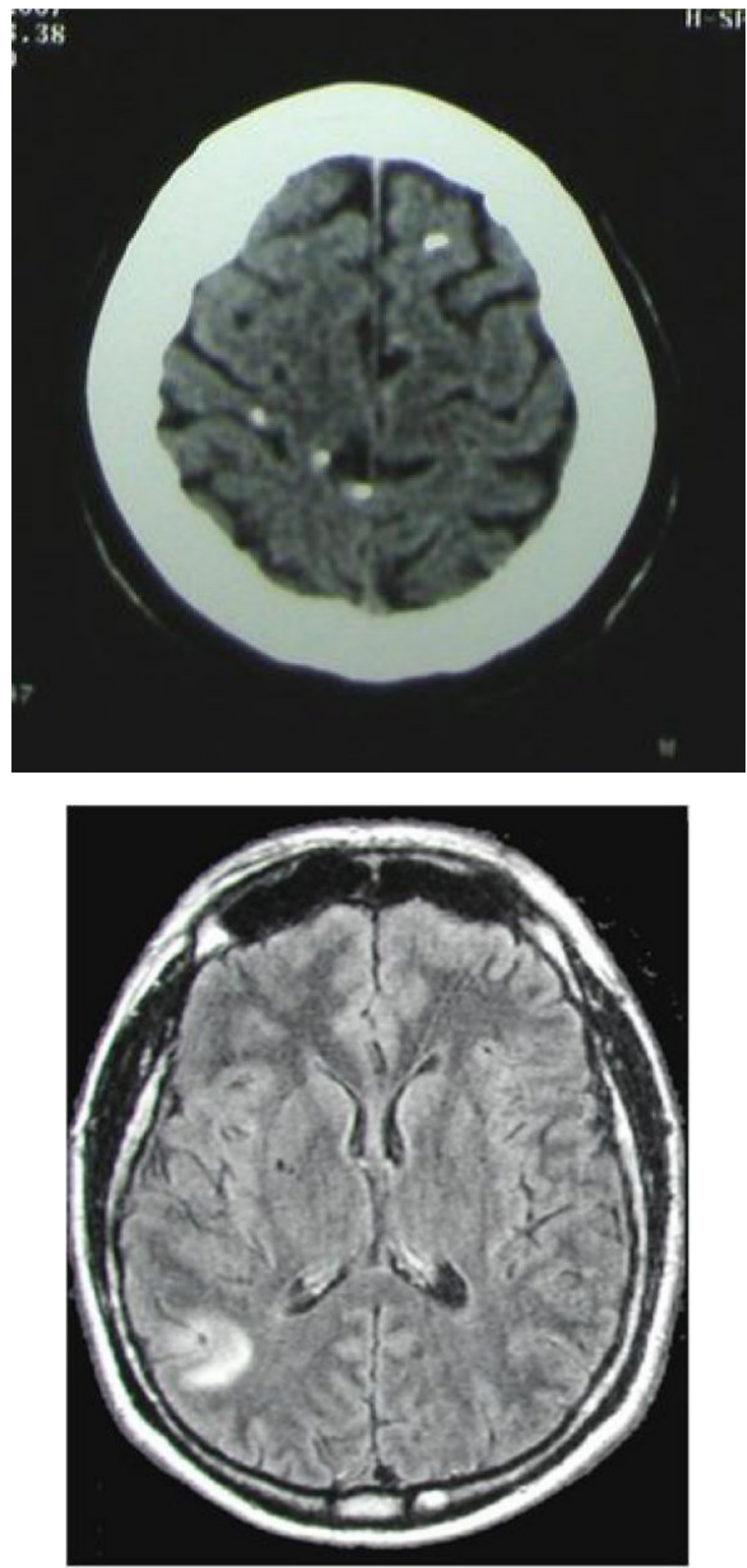

Figure 2. 
Intraparenchymal neurocysticercosis: $2 \mathrm{a}$ - viable cysts (magnetic resonance imaging [MRI], T1 protocol), 2b-degenerating cyst (MRI, T1 protocol after contrast injection); $2 \mathrm{c}$ - calcified lesions (non contrasted computed tomography $[\mathrm{CT}]$ scan); $2 \mathrm{~d}$ - perilesional edema around a calcified lesion (MRI, FLAIR protocol). 

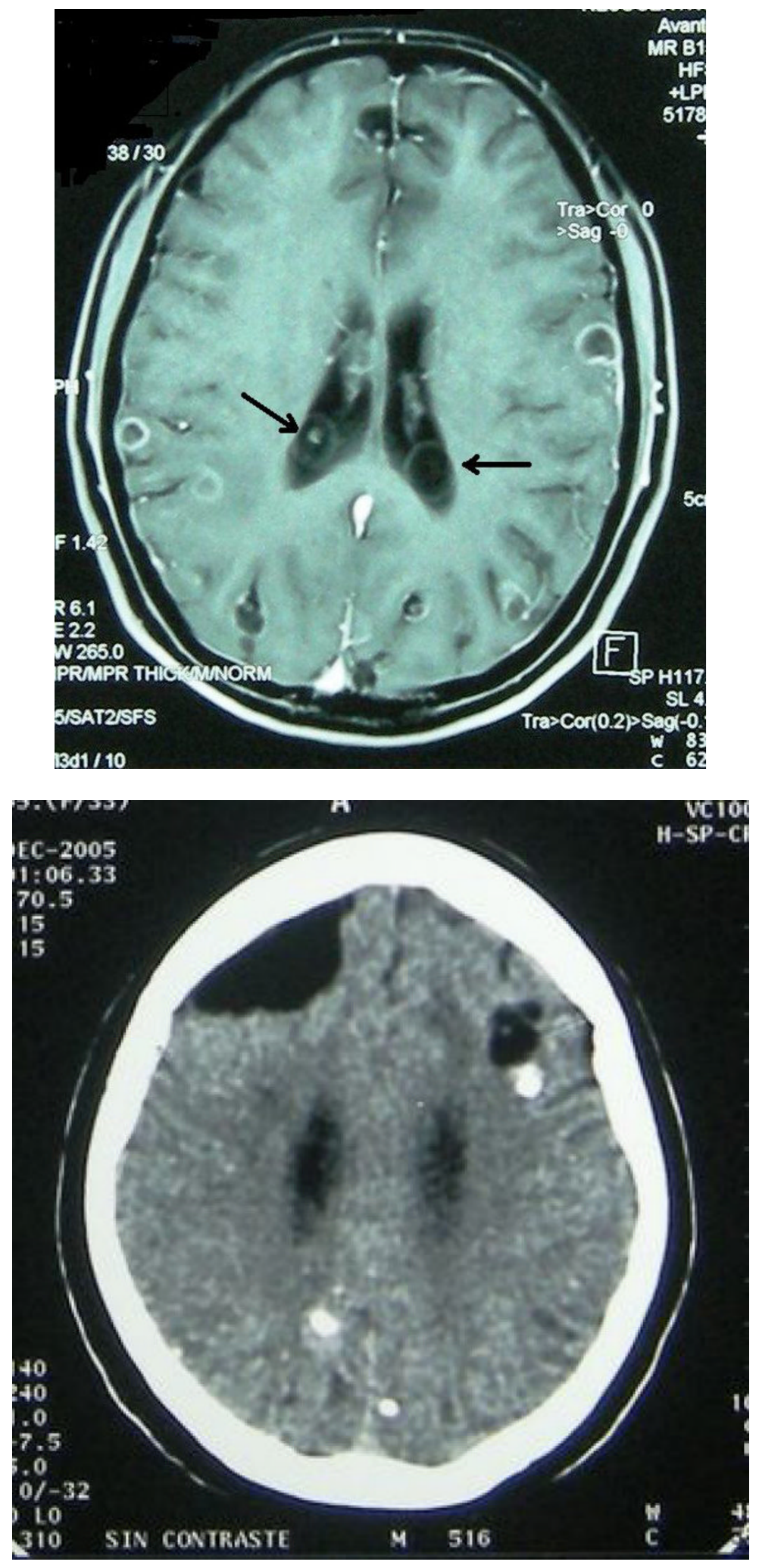

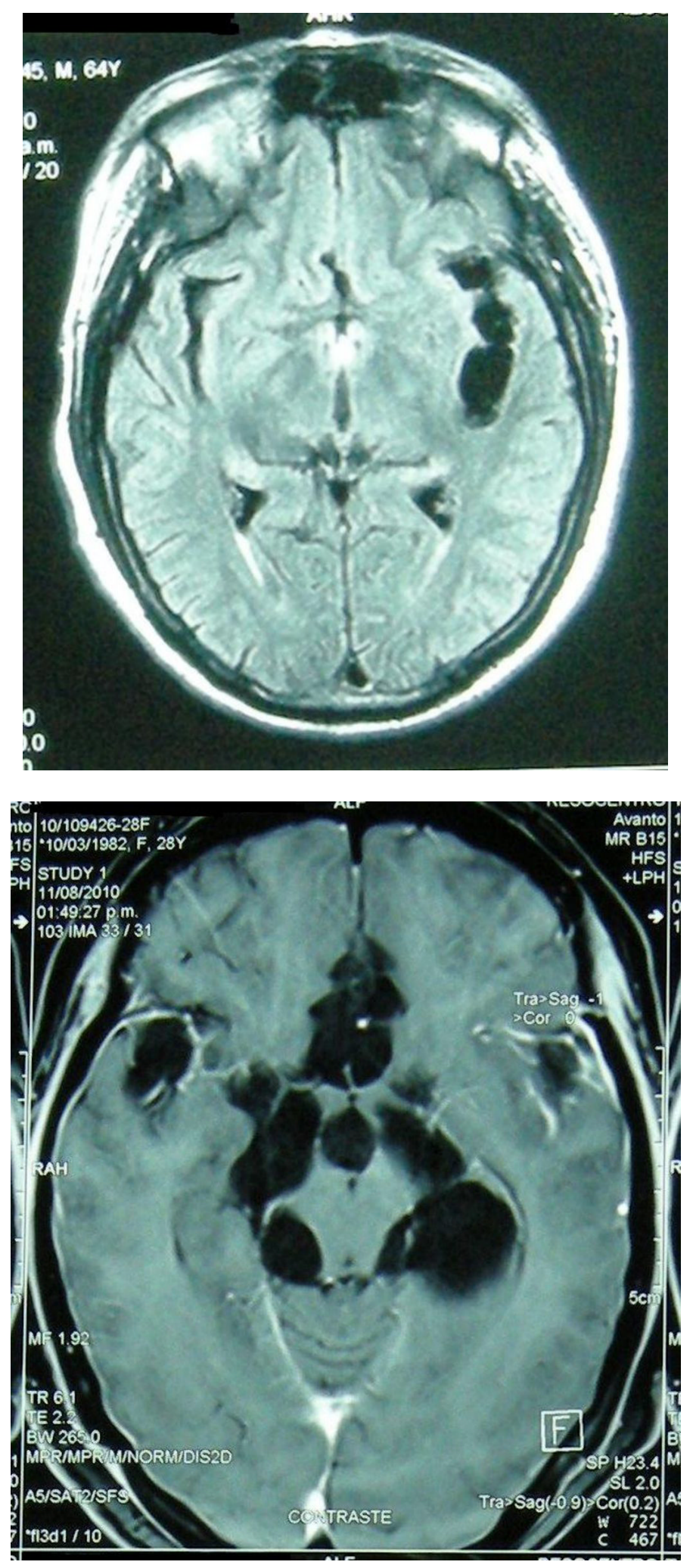

Figure 3. 
Extraparenchymal neurocysticercosis: 3a - intraventricular cyst (with intraparenchymal degenerating enhancing cysts, on MRI, post-contrast T1 protocol); $2 \mathrm{~b}$ - subarachnoid NCC in the brain convexity (with also viable and calcified cysts, on non-contrasted CT); $3 \mathrm{c}$ subarachnoid NCC of the Sylvian fissure (MRI, FLAIR protocol); 3d - basal subarachnoid NCC (MRI, post-contrast T1 protocol). 
Table 1

Characteristics of Intraparenchymal and Extraparenchymal Neurocysticercosis

\begin{tabular}{|l|l|l|}
\hline Characteristic & Parenchymal & $\begin{array}{l}\text { Extraparenchymal including } \\
\text { spinal NCC }\end{array}$ \\
\hline Pathology & $\begin{array}{l}\text { Typical cyst or granuloma, } \\
\text { calcification }\end{array}$ & $\begin{array}{l}\text { Giant Sylvian cysts, ventricular } \\
\text { cysts, basal subarachnoid NCC } \\
\text { ("racemose"). Chronic } \\
\text { inflammation, fibrosis }\end{array}$ \\
\hline Presentation & $\begin{array}{l}\text { Seizures caused by inflamed } \\
\text { cyst or degenerating lesion, } \\
\text { headache, focal neurological } \\
\text { findings }\end{array}$ & $\begin{array}{l}\text { Mass effects, hydrocephalus from } \\
\text { mechanical obstruction or non } \\
\text { communicating, headache, visual } \\
\text { problems, cranial nerve deficits, } \\
\text { infarcts }\end{array}$ \\
\hline Diagnosis & $\begin{array}{l}\text { Imaging with characteristic } \\
\text { cyst, calcifications. Multiple } \\
\text { compatible lesions. }\end{array}$ & $\begin{array}{l}\text { Characteristic cyst in ventricles, } \\
\text { Other sites are non diagnostic } \\
\text { unless present with simultaneous } \\
\text { intraparenchymal involvement }\end{array}$ \\
\hline Treatment & $\begin{array}{l}\text { Short, usual dose } \\
\text { anthelminthics, limited } \\
\text { corticosteroids }\end{array}$ & $\begin{array}{l}\text { May require long-term and } \\
\text { repeated anthelminthics, long-term } \\
\text { corticosteroids, methotrexate as } \\
\text { possible steroid sparing }\end{array}$ \\
\hline Response & $\begin{array}{l}\text { Usually cysticidal, cure rates } \\
\text { low, responds to retreatment }\end{array}$ & Variable, relapse common \\
\hline Prognosis & $\begin{array}{l}\text { Good, possible seizure } \\
\text { relapses }\end{array}$ & $\begin{array}{l}\text { Not as good. Shunt obstruction is } \\
\text { common, sizable mortality }\end{array}$ \\
\hline
\end{tabular}

